\title{
The crystallization of polypropylene in multiwall carbon nanotube-based composites
}

Carlos Marco, Mohammed Naffakh, Marián A. Gómez, Gonzalo Santoro and Gary Ellis*

Departamento de Física e Ingeniería de Polímeros, Instituto de Ciencia y Tecnología de Polímeros, CSIC, c/ Juan de la Cierva, 3, 28006, Madrid, Spain.

Correspondence to: Gary Ellis; e-mail: gary@ictp.csic.es

Acknowledgements: This work was supported by the Spanish Ministry of Science \& Innovation (MICINN), Project number MAT2006-13167-C01. The authors wish to thank Drs. Wolfgang Maser and Ana Benito for supplying the MWCNTs. X-Ray experiments were performed at the Soft condensed Matter A2 beamline of the HASYLAB synchrotron (DESY- Hamburg, Project number I-20080056 EC), supported by the European Commission. Finally, G.S. acknowledges support from the FPI program of the MICINN.

This article first appeared in Polymer Composites, vol. 32, pages 324-333 (2011), a publication of the Society of Plastics Engineers 


\section{ABSTRACT}

The crystallization process of isotactic polypropylene (iPP) was studied under both dynamic and isothermal conditions for a series of multi-wall carbon nanotube (MWCNT) composites with nanotube concentrations between $0.1-1.0 \%$ by weight. The nucleation activity of the nanofillers was confirmed for both dynamic and isothermal crystallization, and was shown to be composition dependent. The effect of the nanofiller on the crystallization of iPP was discussed using the temperature coefficients obtained to determine the interfacial free energy and free energy of nucleation. The basal interfacial free energy decreased with respect to that of neat iPP by up to $15 \%$ for as little as $0.1 \%$ MWCNT, subsequently decreasing linearly with increasing nanotube concentration. This behavior is in line with the crystallization behavior of iPP with conventional nucleating agents. 


\section{INTRODUCTION}

Isotactic polypropylene is one of the most important contemporary semicrystalline polymers with a wide range of applications where the mechanical properties are frequently modified by the addition of fillers or nucleating agents [1-5]. The use of carbon nanotubes (CNTs) as fillers in polymeric nanocomposites has received much attention $[6,7]$ notably due to their unique structure, with a high aspect ratio and extraordinary mechanical properties, making them very attractive candidates for polymeric materials reinforcement [8-11]. A number of different studies have been undertaken in order to evaluate the influence of CNT fillers on the rheological, mechanical and electrical properties of iPP [12-23]. In iPP composites, factors such as the microstructure and degree of crystallinity, the crystallization rate and the crystalline morphology are considerably influenced by the presence of nanofillers or reinforcements present in the polymeric matrix. The understanding and control of these parameters related to the crystalline solid state of iPP is fundamental for the design of its properties.

Recently there has been a growing interest in the influence of CNTs on the crystallization behavior of iPP, both with regard to their nucleating activity and the generation of polymorphic crystalline forms [24-30]. However, whilst the nucleation activity of multi-wall carbon nanotubes (MWCNTs) on the crystallization of iPP is known there is relatively little information in the literature on the influence of MWCNTs on the crystallization behavior of iPP [17, 23, 26, 31-38], and to date no contrasted information relating to the energetic parameters associated with nucleation in iPP under isothermal conditions is available. In order to analyze the properties of polypropylene blends and composites, a thorough understanding of the characteristics of the crystallization process, under both dynamic and isothermal conditions, is 
fundamental, including the nucleation mechanisms and crystallization kinetics. For this reason the aims of the present work are, firstly to compare the crystallization behavior of iPP under the influence of a MWCNT nanofiller in both dynamic and isothermal conditions, and secondly, to analyze the temperature coefficients under isothermal crystallization and determine the interfacial free energy and free energy of nucleation involved in the nucleation process.

\section{EXPERIMENTAL}

Materials and processing

A commercial iPP was employed, ISPLEN ${ }^{\circledR}$ PP 070 G2M (Repsol-YPF, Móstoles, Spain) with a melt flow index of $10.0 \mathrm{~g} / 10 \mathrm{~min}\left(230^{\circ} \mathrm{C} / 2.16 \mathrm{~kg}\right)$ and a density of 0.902 g. $\mathrm{cm}^{-3}$. The MWCNTs were grown by the arc discharge method [39] by Dr. W. Maser and Dr. A. Benito (Instituto de Carboquímica, CSIC, Zaragoza, Spain). The quality of the nanotubes was evaluated using Raman spectroscopy [40] based on the $\mathrm{I}_{\mathrm{G}} / \mathrm{I}_{\mathrm{D}}$ ratio [41] where $I_{G}$ is the integrated intensity of the G-mode ( $\mathrm{sp}^{2}$ carbon, ordered structure) centered at around $1575 \mathrm{~cm}^{-1}$ and $\mathrm{I}_{\mathrm{D}}$ is that corresponding to the D-mode ( $\mathrm{sp}^{3}$ carbon, disorder or defect mode) centered at around $1280 \mathrm{~cm}^{-1}$. From averaged Raman spectra an $\mathrm{I}_{\mathrm{G}} / \mathrm{I}_{\mathrm{D}}$ ratio of $4.42 \pm 0.01$ was observed.

PP/MWCNT composites were prepared by melt blending using a Haake MiniLab Rheomex CTW5 co-rotating twin-screw extruder (Thermo Scientific, Madison, USA) with a volume of $7 \mathrm{~cm}^{3}$. With the aim of improving the dispersion of the nanotubes in the matrix, $25 \%$ by weight of iPP in powdered form, produced by cryogenic impact milling of granules using a SPEX Model 6770 Freezer Mill (SPEX CertiPrep Ltd, Stanmore, UK) was mixed with the corresponding concentration of MWCNTs to produce a powdered masterbatch for each composition. Each masterbatch 
was then mixed with the iPP granules and introduced into the extruder. Recent improvements in this premixing methodology have been demonstrated to significantly enhance the thermal and mechanical properties of polymer-MWCNT composites [42] through improved dispersion. The following blending conditions were employed: screw speed $=100 \mathrm{rpm}$, temperature $=200{ }^{\circ} \mathrm{C}$, and processing time $=5 \mathrm{~min}$. Four different compositions were prepared with $0.1 \%, 0.25 \%, 0.5 \%$ and $1 \%$ by weight of nanotubes. A sample of neat iPP was also prepared under the same conditions.

\section{Characterization techniques}

Dynamic crystallization experiments were undertaken in a Mettler TA4000/DSC30 differential scanning calorimeter (Mettler-Toledo Intl Inc.), and the data obtained was evaluated using STAR ${ }^{\mathrm{e}} 9.10$ software. Aluminum capsules were used with sample weights of approximately $12 \mathrm{mg}$ studied under an inert nitrogen atmosphere flow at a rate of $25 \mathrm{ml} \cdot \mathrm{min}^{-1}$. Several cooling cycles from the melt were undertaken at cooling rates, $R$, of $20,10,5$ and $2{ }^{\circ} \mathrm{C} \cdot \mathrm{min}^{-1}$, followed by heating cycles at $5^{\circ} \mathrm{C} \cdot \mathrm{min}^{-1}$ over the interval of temperatures between 30 and $210^{\circ} \mathrm{C}$. The melting temperature, $T_{m}$, and the crystallization temperature, $T_{p}$, were determined at the maximum of the melting endotherm observed during the heating scan and the minimum of the crystallization exotherm observed during the cooling scan, respectively. The elimination of the thermal history prior to the crystallization of polypropylene was achieved by maintaining the samples for five minutes at a residence temperature of $210^{\circ} \mathrm{C}$ in the melt [43], in order to eliminate memory effects and to assure the maximum thermal stability of the components.

Isothermal crystallization was studied using a Perkin-Elmer DSC7/7700/UNIX differential scanning calorimeter (Perkin-Elmer España SL, Madrid, Spain), calibrated 
with indium $\left(T_{m}=156.6^{\circ} \mathrm{C}, \Delta H_{m}=28.45 \mathrm{~kJ} \mathrm{~kg}^{1}\right)$ and zinc $\left(T_{m}=419.4{ }^{\circ} \mathrm{C}, \Delta H_{m}=\right.$ $108.37 \mathrm{~kJ} \mathrm{~kg}^{1}$ ). Once again, approximately $12 \mathrm{mg}$ samples were weighed in aluminum capsules, and studied under a nitrogen gas flow of $25 \mathrm{ml} \mathrm{min}{ }^{-1}$. After the thermal history was erased prior to crystallization, as commented previously, the samples were cooled from the melt to each crystallization temperature, $T_{c}$, at a rate of $64{ }^{\circ} \mathrm{C} \mathrm{min}^{-1}$. The exotherm was subsequently registered as a function of time until crystallization was considered to be complete. The isothermal step was followed by a heating cycle up to $210{ }^{\circ} \mathrm{C}$ at a rate of $5{ }^{\circ} \mathrm{C} \mathrm{min}^{-1}$. The time associated with each degree of conversion, $\tau_{i}$ was obtained by integration of the corresponding crystallization exotherms. The crystallization rate, $G$, was analyzed using values of $\tau_{0.1}$, which correspond with the time required to reach a degree of crystalline conversion of $10 \%$. If we consider that $G$ $\sim\left(\tau_{0.1}\right)^{-1}$, this parameter is representative of the overall crystallization rate for each crystallization temperature.

The apparent transition enthalpy, $\Delta H_{a p p}$ was determined from the area under the crystallization curve, taking the upper and lower limits in the corresponding deviations from the baseline. The conversion from apparent enthalpy to degree of crystallinity, (1ג), was calculated using the following equation:

$$
(1-\lambda)=100\left(\frac{\Delta H_{a p p}}{w \Delta H_{m}}\right)
$$

where $\Delta H_{m}=207.1 \mathrm{~kJ} \mathrm{~kg}^{-1}$, corresponding to the melting enthalpy of $100 \%$ crystalline iPP [44], and $w$ is the weight fraction of MWCNT.

X-ray diffraction experiments employing synchrotron radiation were undertaken at HASYLAB, in the DESY Synchrotron in Hamburg. Simultaneous measurements at wide angles, WAXS, and small angles, SAXS, were obtained in real time using the angular distribution of dispersed energy method employing a double focus camera 
comprised of a Germanium $\mathrm{Ge}^{111}$ monochromator and a series of quartz focusing mirrors. The wavelength corresponding to the (111) plane of $\mathrm{Ge}^{111}$ is $0.15 \mathrm{~nm}$. Linear Gabriel WAXS and SAXS detectors were used. The sample-to-detector distance for SAXS was $2.36 \mathrm{~m}$ and that for WAXS was $0.135 \mathrm{~m}$, with the entire system maintained under vacuum conditions. The detectors were calibrated with standards; poly(ethylene terephthalate) in the case of WAXS, and RTT (rat tail tendon) in the case of SAXS. Film samples were prepared by compression and crystallization in a Mettler FP90/FP82 HT temperature cell (Mettler-Toledo Intl Inc.).

\section{RESULTS AND DISCUSSION}

\section{Dynamic Crystallization}

The crystallization exotherms of neat iPP and iPP in its respective binary composites, obtained in dynamic conditions by cooling from the melt, were observed to shift to lower temperatures and broaden as the cooling rate was increased. This is directly related to the formation of smaller crystals with a wider distribution of crystallite sizes. Figure 1 shows crystallization exotherms of neat iPP and the iPP/MWCNT composites at a cooling rate of $10{ }^{\circ} \mathrm{C} \cdot \mathrm{min}^{-1}$ where a marked shift to higher $T_{p}$ values can be observed. In Figure 2 the variation of $T_{p}$ with concentration of MWCNT for neat iPP and all the materials analyzed is given. $T_{p}$ is affected by the presence of the nanotubes at all cooling rates, for example, a significant increase of around $6^{\circ} \mathrm{C}$ in this parameter with $0.1 \%$ MWCNT can be observed at a cooling rate of $10^{\circ} \mathrm{C} \cdot \mathrm{min}^{-1}$. At higher MWCNT concentrations the value of $T_{p}$ for iPP continues to rise and tends to stabilize for the highest concentrations of 0.5 y $1 \%$, where increments of around $8^{\circ} \mathrm{C}$ in the value of $T_{p}$ were registered, Table 1 . This effect on the crystallization of iPP in the composites must be attributed to a crystalline induction effect by the 
MWCNTs that favors the nucleation stage of iPP, and consequently increases the crystallization rate, and is manifested by a higher crystallization temperature than neat iPP for the same cooling rate. These results are in agreement with those described recently for iPP/MWCNT nanocomposites prepared from the melt with concentrations between 0.5 - 5\% by weight of MWCNT [17, 23, 26, 35, 38-45]. The levels of crystallinity developed during the cooling cycles, and the values obtained for $T_{m}$ in the heating cycle subsequent to crystallization, were practically identical for both neat iPP and the nanocomposites. This observation is consistent with some of the results observed in the literature [16, 25, 33].

Under the previously described dynamic crystallization conditions, iPP crystallized in the $\alpha$, or monoclinic form. The WAXS diffractograms of the binary iPP/MWCNT composites, Figure 3a, only present reflections associated to the crystalline planes characteristic of the monoclinic polymorph of iPP [46].

With a view to analyzing the possible variations in the lamellar structure of polypropylene room temperature SAXS diffractograms were measured for all samples after the dynamic crystallization from the melt at $10^{\circ} \mathrm{C} \cdot \mathrm{min}^{-1}$, Figure $3 \mathrm{~b}$. The long spacing, $L$, calculated from the reciprocal of the maximum scattering value, $s_{\max }$, obtained from the Lorenz corrected intensity profile, increased from a value of $10 \mathrm{~nm}$ for neat iPP to $13 \mathrm{~nm}$ for the 1\% MWCNT nanocomposite, Table 1 . If one takes into account the reproducibility of the melting temperature of iPP in the nanocomposites with respect to that of neat iPP commented previously, it seems more reasonable to associate the variations observed in the long spacing to the possible location of the nanotubes in the interlamellar spacings rather than to an increase in the size of the iPP crystallites. It seems evident that during the crystallization process a migration of the MWCNTs from the lamellar growth front must take place as they are progressively 
excluded from the crystals, generating aggregates that are located either in the interspherulitic spaces, in the interphase regions of the crystalline lamellae, or in the amorphous regions of the lamellar stacks. These previously commented results agree with recent work on iPP/MWCNT nanocomposites with 1 y $2 \%$ of nanotubes prepared from xylene solutions [34].

The evolution of the crystallization process from the melt state to the organized state was studied by following the variation in conversion, or the percentage of crystalline transformation, as a function of temperature for the various cooling rates analyzed. The tendency shown by the conversion curves, with a much accelerated primary crystallization even at the lowest cooling rates, did not allow the application of the Ozawa treatment for the analysis of non-isothermal crystallization kinetics [47].

On the other hand, when we take into account the variation in the crystallization temperature, considered as the minimum in the $\mathrm{T}_{\mathrm{p}}$ with $R$, it is possible to estimate the nucleating activity of the MWCNTs, $\Phi$, using the method developed by Dobreva $\mathrm{y}$ Gutzow [48], where the relationship between the undercooling of the system on crystallization, $\Delta T_{p}$ and the crystallization rate is given by:

$$
\log R=A-\left(B / 2.303 \Delta T_{p}^{2}\right)
$$

for the case of homogeneous nucleation, and by:

$$
\log R=A-\left(B^{*} / 2.303 \Delta T_{p}^{2}\right)
$$

for heterogeneous nucleation, where $\Delta T_{p}=T_{m}-T_{p}$.

If we consider that when crystallization takes place in a temperature range relatively close to the melting temperature, the potential barrier for crystalline growth is much smaller than that corresponding to the crystalline nucleation process. Thus, crystallization will be governed by the crystalline nucleation stage, and the nucleation activity is given by: 


$$
\Phi=B^{*} / B
$$

which can be obtained from the gradients of eq. 2 and 3. This nucleation efficiency is directly related with the energy of adhesion between the nucleating substrate and the nucleated crystalline phase, $\beta$, by the expression:

$$
\Phi=1-(\beta / 2 \sigma)
$$

where $\sigma$ is the specific surface energy at the crystalline interface. When $\beta \rightarrow 2 \sigma, \Phi \rightarrow$ 0 , and the nucleating activity tends to its optimum, whilst on the contrary, when $\beta \rightarrow 0$, $\Phi \rightarrow 1$, and the nucleation activity tends to zero, as occurs in the case of homogeneous nucleation. In Figure 4, eq. 2 and 3 are represented for neat iPP and the compounds analyzed, considering a value of $210^{\circ} \mathrm{C}$ for the thermodynamic equilibrium melting temperature of iPP [49]. The values of $\Phi$ obtained oscillate between 0.88 for a MWCNT concentration of $0.1 \%$ to 0.77 for a concentration of $1.0 \%$.

The nucleation efficiency can also be determined from the variation observed in the crystallization temperature of the iPP matrix in the MWNT nanocomposites with respect to that found in the same matrix by an auto nucleation process at the same cooling rate. In this situation, the concentration and distribution of crystalline nuclei and the nucleus-matrix interaction can be considered ideal, and the nucleation efficiency should be at its maximum [50,51]. Given that the two extremes in the efficiency scale are the non-nucleated matrix and the auto nucleated matrix, the nucleation efficiency, $N E$, can be expressed as:

$$
N E=100\left(T_{p}-T_{p l}\right) /\left(T_{a l}-T_{p l}\right)
$$

where $T_{a l}$ y $T_{p l}$ are the temperatures of crystallization associated with the non-nucleated and auto nucleated matrix, respectively. Considering a value of $T_{p l}=140{ }^{\circ} \mathrm{C}$ [52], values for NE from $27 \%$ to $36 \%$ were obtained for MWCNT concentrations between $0.1 \%$ and $1.0 \%$, for a cooling rate of $10^{\circ} \mathrm{C} / \mathrm{min}$. In Figure 5 , the evolution of both the 
nucleating activity and the nucleating efficiency are compared as a function of the concentration for the PP/MWCNT composites analyzed in this work.

\section{Isothermal crystallization}

The isothermal crystallization behavior of neat iPP has been analyzed over a crystallization temperature range between 126 and $133^{\circ} \mathrm{C}$. Figure $6 a$ shows the evolution of the crystallization exotherms of neat iPP. As the crystallization temperature increased, the exotherms shifted along the time axis. Both the induction time and the width of the exotherms increased, which reflects a reduction in the crystallization rate with decreasing undercooling of the system, $\Delta T$. The isothermal crystallization behavior of iPP in the nanocomposites was analyzed over the crystallization temperature range between 132 and $144{ }^{\circ} \mathrm{C}$. In this case, the crystallization exotherms of iPP presented shorter induction times and a narrower integral area than those corresponding to neat iPP, and showed an apparent increase in the isothermal crystallization rate, Figure 6b for the case of iPP/MWCNT 0.25\%. This behavior was generalized and occurred over the whole composition range analyzed.

The rate of crystallization, $G$, was analyzed using the values of $\tau_{0.1}$ which corresponds to the time necessary to reach a degree of crystalline transformation of 10\%. This parameter represents the global crystallization rate for each crystallization temperature considering that $G \sim\left(\tau_{0.1}\right)^{-1}$. A pronounced change in the crystallization rate was be observed as the temperature increased, in other words, as the undercooling decreased, Figure 7. Also the apparent increase in the isothermal crystallization rate of iPP on the addition of MWCNT in the binary nanocomposites, shown previously by comparison of the crystallization exotherms, was now exhibited over the full 
temperature range analyzed. Thus, it can be deduced that the nanofiller produced a nucleating effect on the crystallization of iPP.

A saturation effect of the nucleating activity of the MWCNTs on iPP has been described recently in the literature for MWCNT concentrations between $0.2-1.0 \%$ by weight [53]. Also, confinement effects on the polymer chains in the crystallization of nylon-6,6 in the presence of MWCNTs have been reported by Li et al [54]. Neither of these effects have been observed in the present work.

The crystallization kinetics was analyzed using the Avrami and Göler-Sachs models [55]. The Avrami model takes into account the perturbation of adjacent crystalline nuclei in the crystallization process, and the Göler-Sachs model assumes free crystalline growth. The Avrami model can be represented in the following manner:

$$
\ln (1-\theta)=k t^{n}
$$

where $\theta$ is the degree of crystalline conversion, $k$ is the rate constant and $n$ is the Avrami exponent that reflects the mode of crystalline nucleation and growth. In Figure 8 the variation in the crystalline conversion as a function of time is given for neat iPP and the iPP/MWCNT $0.25 \%$ composite. From these data, by the application of the Avrami model for each crystallization temperature over the temperature range analyzed, considering a crystalline transformation under 25\%, values of the Avrami exponent, $n \approx$ 3 were determined in all cases. This value implies a three-dimensional heterogeneous crystal growth that is practically unchanged with the addition of MWCNT. Values of $n$ $\approx 3$ have also been found for some iPP/SWCNT composites [25], and values between 2 and 3 for both iPP/SWCNT [24, 30], and iPP/MWCNT composites [34, 35].

The determination of this parameter allowed the analysis of the overall crystallization rate of the crystallization process from the rate constant, $k$, at each crystallization temperature by the following expression [56]: 


$$
k=\frac{\ln 2}{\tau_{0.5}^{n}}
$$

where $\tau_{0,5}$ is the time needed to reach $50 \%$ crystalline transformation. Values of $k$ obtained for each composite and crystallization temperature are given in Table 2. For example, at a $T_{c}$ of $133^{\circ} \mathrm{C}$, the values of $k$ can be observed to vary from $1.5 \times 10^{-4} \mathrm{~min}^{-1}$ for neat iPP, to $6.5 \times 10^{-2} \mathrm{~min}^{-1}$ for the composition with $0.5 \%$ by weight MWCNT. These results confirm the nucleating activity of the MWCNT on the crystallization of iPP in isothermal conditions. There is only one antecedent in the literature that presents values for the rate constant in iPP/MWCNT compounds [35]. These were determined by extrapolation from the Avrami expression under isothermal crystallization conditions at much higher undercoolings than those employed in the present work, and variations in the values of $k$ were reported between $1.5 .10^{-7} \mathrm{~s}^{-1}$ and $1.8 .10^{-4} \mathrm{~s}^{-1}$ for neat iPP and the composite with 1\% MWCNT, respectively [35]. Hardly any k-value data have been published for nanocomposites of iPP with SWCNT [25, 30].

\section{Melting behavior after isothermal crystallization}

After isothermal crystallization at different crystallization temperatures, the nanocomposites were heated at $5{ }^{\circ} \mathrm{C} \min ^{-1}$ to the molten state. The melting behavior of neat iPP showed a single endotherm with a well defined maximum, $T_{m} I$, and some asymmetry in the lower temperature region, where shoulders, $T_{m} I I$, appeared for the higher crystallization temperatures, Figure 9a. Both the main endothermic maximum and the associated lower temperature shoulder shifted to higher temperatures with increasing crystallization temperature, $T_{c}$. This is related to the formation of crystals whose sizes increase with the reduction in the degree of undercooling. The shift of both endotherms with increasing $T_{C}$ suggests the existence of partial crystal size segregation in the isothermally formed crystallites. The smaller crystals generated the lower 
temperature shoulders, and the enthalpy contribution of the melting of the larger more perfect crystals was included in the higher temperature endotherm. However, a contribution from the melting-recrystallization-melting of more imperfect crystals cannot be ruled out $[45,57]$.

From the analysis of the wide angle X-ray diffractograms recorded under isothermal crystallization conditions, only reflections associated with the monoclinic structure of iPP were detected. No evidence of the fundamental crystalline reflection at $2 \theta=16.2^{\circ}$ corresponding to the $(3,0,0)$-plane of the trigonal structure [45] was observed.

The presence of the MWCNT does not substantially modify the melting behavior of iPP. In Figure 9b-c the double endotherm phenomenon was still observed for compositions of 0.1 and $0.25 \%$ MWCNT, but in these cases there was a clear increase in the values of $T_{m} I I$ and $T_{m} I$ with respect to the melting of neat iPP as a consequence of the formation of the crystallites at higher crystallization temperatures, i.e. at smaller undercooling.

\section{Temperature coefficient}

When polymeric materials are crystallized with low undercooling, i.e. high crystallization temperatures, the crystallization rate is higher the greater the undercooling. This implies that the crystallization process is controlled by the nucleation stage, i.e. by the free energy needed for the formation of a stable crystallite or the free energy of nucleation, $\Delta G^{*}$.

In agreement with the kinetic theory of crystallization [58-60], independent of the type of regime, the crystallization rate $G$ can be given by: 


$$
\log G+\left[\frac{U}{2.3 R\left(T_{c}-T_{\infty}\right)}\right]=\log G_{0}-\left(\frac{K_{g(I I I)}}{2.3 T_{c} \Delta T}\right)
$$

where $K_{g(I I I)}=4 \sigma_{u} \sigma_{e} b_{0} T_{m}{ }^{0} / k \Delta H_{m}$ for Regime III [61-64], $k$ being the Boltzmann constant, $1.38 \times 10^{-26} \mathrm{~kJ} \mathrm{~K}^{-1}, b_{0}=6.26 \AA$, represents the thickness of a crystalline monolayer added during growth, $\sigma_{e}$ and $\sigma_{u}$ are the basal and lateral interfacial free energies of the crystallite, respectively, and $U / 2.3 R\left(T_{c^{-}} T_{\infty}\right)$ represents the transport term through the liquid - crystal interface at the crystallization temperature $T_{c}$ [65]. The temperature $T_{\infty}$ is that at which the viscosity of the system is infinite, and is equivalent to the value $T_{g}-30$ which is $231.1 \mathrm{~K}$ for polypropylene. The parameter $U$ is variable, and a value of $6.270 \mathrm{~kJ} \mathrm{kmol}^{-1}$ is generally adopted. The representation of the first term of equation 8 versus $1 / 2.3 R T_{c} \Delta T$ is presented in Figure 10 for all of the samples analyzed.

The literature values for $\Delta H_{m}$ are both variable and dispersed and are fundamentally conditioned by the method of determination [46]. However, it is possible to eliminate the influence of this parameter in the comparative analysis of the values of the interfacial free energies by applying the approximation of Hoffman, Davis and Lauritzen [58], which establishes that the interfacial free energy can be given by the following expression,

$$
\sigma_{u}=\alpha \Delta H_{m}\left(a_{0} b_{0}\right)^{1 / 2}
$$

where $\alpha \approx 0.1$ and $a_{0} b_{0}=34.37 \AA^{2}$ which represents the chain cross section in the iPP crystal, and the values of the basal interfacial free energy can be obtained from the following expression:

$$
\sigma_{e}=\frac{k K_{g(I I I)}}{4 b_{0} T_{m}^{0} \alpha\left(a_{0} b_{0}\right)^{1 / 2}}
$$


Under these considerations, the values obtained for the basal interfacial free energy were 1.38, 1.32, 1.28 and $1.15 \times 10^{-8} \mathrm{~kJ} \mathrm{~cm}^{-2}$ for $0.1,0.25,0.5$ and $1 \%$ MWCNT, respectively. From the data obtained in this work, it seems evident that the reduction in the values of $\sigma_{e}$ in the binary iPP/MWCNT composites, compared to the value of $1.61 \times 10^{-8} \mathrm{~kJ} \mathrm{~cm}^{-2}$ in the case of neat iPP, was associated with the nucleating effect of the MWCNT, in agreement with Beck [66], and are similar to those which occur in the presence of nucleating agents [67-70], nanofillers [71], or different types of fibers where transcrystallization is observed [49,72]. Recently Razavi-Nouri et al. [73] observed a progressive decrease in the basal interfacial free energy associated with the isothermal crystallization of iPP in PP-SWCNT composites up to a nanotube concentration of $0.5 \%$. However, to our knowledge, the values in the literature for $\sigma_{e}$ in the isothermal crystallization of iPP in composites with MWCNTs is very scarce. Only Zhou et al. [36] have reported a value of $1.1 \times 10^{-8} \mathrm{~kJ}^{\mathrm{cm}} \mathrm{cm}^{-2}$ for neat iPP, increasing to $1.4 \times 10^{-8} \mathrm{~kJ} \mathrm{~cm}^{-2}$ in the presence of $0.5 \%$ MWCNT with a subsequent reduction to $0.75 \times 10^{-8} \mathrm{~kJ} . \mathrm{cm}^{-2}$ for $1 \%$ MWCNT. However, no justification for this variation with respect to the nucleation activity of the nanotubes is given.

It is accepted that the presence of a foreign substrate in the iPP melt frequently reduces the critical size of the crystalline nucleus necessary for subsequent growth, since the generation of an interphase between the polymeric crystal and the substrate may be less restricted than the creation of a crystalline nucleus from the melt [74]. As a matter of fact, heterogeneous nucleation occurs through the reduction of the free energy of nucleation, which gives rise to a higher nucleation rate and, as such, a higher crystallization rate.

The free energy of nucleation, i.e. the free energy necessary for the formation of a nucleus of a critical size, is given by the expression, 


$$
\Delta G^{*}=\frac{4 b_{0} \sigma_{u} \sigma_{e} T_{m}^{0}}{\Delta H_{m} \Delta T}
$$

$\Delta G^{*}$, which increases with smaller undercooling, was lower for the iPP/MWCNT composites than for neat iPP at the same crystallization temperature, Figure 11, which confirms that the energy barrier for nucleation is lowered in the presence of the MWCNT component, leading to an increase in the overall crystallization rate.

It is clear that the viscosity of the iPP melt increases with the concentration of MWCNT, and consequently the energy required to transport the polymeric chains to the growing crystalline lamellae also increases. This increase in the transport energy, which is opposed to the increase in the overall crystallization rate, is mitigated by the reduction in the free energy of nucleation which favors the crystallization process, such that the resulting balance in the process is an increase in the rate of crystallization with increasing MWCNT content over the concentration range studied.

\section{CONCLUSIONS}

The analysis of the crystallization of iPP in its composites with MWCNTs by differential scanning calorimetry, under both isothermal and dynamic conditions, has demonstrated that both the crystallization temperature of iPP obtained under dynamic conditions and the isothermal crystallization rate are affected by the presence of MWCNT, showing a significant increase in both parameters. This is composition dependent and confirms the existence of a nucleation effect on the crystallization of iPP due to the presence of MWCNT dispersed in the iPP melt. This nucleation phenomenon is manifested by a reduction in the values of basal interfacial free energies for iPP, and a subsequent reduction in the free energy of nucleation and an increase in the global crystallization rate, whilst maintaining the monoclinic crystalline structure of iPP. The 
presence of MWCNTs only has a slight influence on the double-endothermic melting behavior of iPP, manifesting small but clear increments in the melting temperatures.

\section{REFERENCES}

1. X. Liu and Q. Wu, Polymer 42, 10013 (2001)

2. W. Qiu, K. Mai and H. Zeng, J. Appl. Polym. Sci., 77, 2974 (2000)

3. E. Assouline, S. Pohl, R. Fulchiron, J.F. Gerard, A. Lustiger, H.D. Wagner and G. Marom, Polymer 41, 7843 (2000)

4. C. Marco, G. Ellis, M.A. Gómez and J.M. Arribas, Recent Res. Devel. Appl. Pol. Sci., 1, 587 (2002)

5. W. Su, M. Ge and P. He, J. Polym. Sci. Polym. Phys., 40, 408 (2002)

6. H.D. Wagner, O. Lourie, Y. Feldman and R. Tenne, Appl. Phys. Lett., 72, 188 (1998)

7. R. Dagani, Chem. Eng. News 77, 25 (1999)

8. L.S. Schadler, S.C. Giannaris and P.M. Ajayan, Appl. Phys. Lett., 73, 3842 (1998)

9. F.T. Fischer, R.D. Bradshaw and L.C. Brinson, Appl. Phys. Lett., 80, 4647 (2002)

10. S. Curran, P. Ajayan, W. Blau, D. Carrol, J. Coleman, A. Dalton, A.P. Davey, B. McCarthy and A. Stevens, Adv. Mat., 10, 1091 (1998)

11. M. Alexandre and P. Dubois, Mat. Sci. Eng., 28, 1 (2000)

12. T. Kashiwagi, E. Grulke, J. Hilding, K. Groth, R. Harris, K. Butler, J. Shields, S. Kharchenko and J. Douglas, Polymer 45, 4227 (2004)

13. T.E. Chang, L.R. Jensen, A. Kisliuk, R.B. Piper, R. Pyrz and A.P. Sokolov, Polymer 46, 439 (2005)

14. K. Lozano and E.V. Barrera, J. Appl. Polym. Sci., 79, 125 (2001)

15. S. Kumar, H. Doshi, M. Srinivasarao, J.O. Park and D.A. Schiraldi Polymer 43, $1701(2002)$ 
16. W.E. Dondero and R.E. Gorga, J. Polym. Sci. Polym. Phys., 44, 864 (2006)

17. Z. Zhou, S. Wang, Y. Zhang and Y. Zhang, J. Appl. Polym. Sci., 102, 4823 (2006)

18. J.C. Kearns and R.L. Shambaugh, J. Appl. Polym. Sci., 86, 2079 (2002)

19. S.H. Lee, H.W. Kim, S.H. Kim and J.R. Youn, Eur. Polym. J., 44, 1620 (2008)

20. P. Zhao, K. Wang, H. Yang, Q. Zhang, R. Du and Q. Fu, Polymer 48, 5688 (2007)

21. Y. Xiao, X. Zhang, W. Cao, K. Wang, H. Tan, Q. Zhang, R. Du and Q. Fu, J. Appl. Polym. Sci., 104, 1880 (2007)

22. M. GamB, B.K. Satapathy, M. Thunga, R. Weidisch, P. Pötschke and A. Janke, Makromol. Rapid Commun., 28, 1624 (2007)

23. H. Zhang and Z. Zhang, Eur. Polym. J., 43, 3197 (2007)

24. B.P. Grady, F. Pompeo, R.L. Shambaugh and D.E. Resasco, J. Phys. Chem. B., 106, $5852(2002)$

25. A.R. Bhattacharyya, T.V. Sreekumar, T. Liu, S. Kamar, L.M. Ericson, R.H. Hauge and R.E. Smalley, Polymer 44, 2373 (2003)

26. E. Assouline, A. Lustiger, A.H. Barber, C.A. Cooper, E. Klein, E. Wachtel and H.D. Wagner, J. Polym. Sci. Polym. Phys., 41, 520 (2003)

27. L. Valentine, J. Biagiotti, J.M. Kenny and S. Santucci, Compos. Sci. Tech., 63, 1149 (2002)

28. E.M. Moore, D.L. Ortiz, V.T. Marla, R.L. Shambaugh and B.P. Grady, J. Appl. Polym. Sci., 93, 2926 (2004)

29. L. Valentine, J. Biagiotti, J.M. Kenny and S. Santucci, J. Appl. Polym. Sci., 87, 708 (2003)

30. L. Valentine, J. Biagiotti, M.A. López Manchado, S. Santucci and J.M. Kenny, Polym. Eng. Sci., 44, 303 (2004) 
31. J. Sandler, G. Broza, M. Nolte, K. Schulte, Y.M. Lam and M.S.P. Shaffer, J. Macromol. Sci. Phys., B42, 479 (2003)

32. H.S. Xia, Q. Wang, K.S. Li and G.H. Hu, J. Appl. Polym. Sci., 93, 378 (2004)

33. M.V. Jose, D. Dean, J. Tyner, G. Price and E. Nyairo, J. Appl. Polym. Sci., 103, 3844 (2007)

34. C.A. Avila Orta, F.J. Medellín-Rodríguez, M.V. Dávila Rodríguez, Y.A. Aguirre Figueroa, K. Yoon and B.S. Hsiao, J. Appl. Polym. Sci., 106, 2640 (2007)

35. M.K. Seo, J.R. Lee and S.J. Park, Mat. Sci. Eng., A404, 79 (2005)

36. Z. Zhou, S. Wang, L. Lu, Y. Zhang and Y. Zhang, J. Polym. Sci. Polym. Phys., 45, $1616(2007)$

37. K. Wang, C. Tang, P. Zhao, H. Yang, Q. Zhang, R. Du and Q. Fu, Macromol. Rapid Commun., 28, 1257 (2007)

38. D. Wu D, Y. Sun, L. Wu and M. Zhang, J. Appl. Polym. Sci., 108, 1506 (2008)

39. A.M. Benito, W.K. Maser, M.T. Martínez, Int. J. Nanotech., 2, 71 (2005)

40. Signal-averaged Raman spectra were recorded at a spectral resolution of $4 \mathrm{~cm}^{-1}$ on a Perkin Elmer System 2000-R Fourier transform Raman spectrometer, with a $\mathrm{Nd}^{3+}$ :YAG laser source (200 $\mathrm{mW}$ incident on the sample), and a room temperature InGaAs detector.

41. M. S. Dresselhaus, G. Dresselhaus, A. Jorio, J. Phys. Chem. C, 111, 17887 (2007)

42. G. Santoro, M.A. Gómez, C. Marco, G. Ellis, Macromol. Mater. Eng., 295, 652 (2010)

43. C. Marco, G. Ellis, M.A. Gómez and J.M. Arribas, J. Appl. Polym. Sci., 84, 2440 (2002)

44. H.S. Bu, S.Z.D. Chang and B. Wunderlich, Makromol. Chem. Rapid. Commun., 9, 76 (1988) 
45. M. GamB, B.K. Satapathy, M. Thunga, R. Weidisch, P. Pötschke and J. Jehnichen, Acta Mater., 56, 2247 (2008)

46. J. Karger-Kocsis, J. Polypropylene: Structure, Blends and Composites, Chapman \& Hall (1995) New York

47. T. Ozawa, Polymer 12, 150 (1971)

48. A. Dobreva and I. Gutzow, J. Non-Cryst. Solids 162, 13 (1993)

49. R. Bouza, C. Marco, G. Ellis, Z. Martín, M.A. Gómez and L. Barral, J. Therm. Anal. Cal., 94, 119 (2008)

50. B. Fillon, B. Lotz, A. Thierry and J.C. Wittmann, J. Polym. Sci. Polym. Phys., 31, 1395 (1993)

51. B. Fillon, A. Thierry, B. Lotz and J.C. Wittmann, J. Therm. Anal. Cal., 42, 721 (1994)

52. C. Marco, M.A. Gómez, G. Ellis and J.M. Arribas, J. Appl. Polym. Sci., 84, 1669 (2002)

53. D. Xu and Z. Wang, Polymer 49, 330 (2008)

54. L.Y. Li, C.Y. Li, C.Y. Ni, L.X. Rong and B. Hsiao, Polymer 48, 3452 (2007)

55. L. Mandelkern, Crystallization of polymers, $2^{\text {nd }}$ Ed., Vol. I. Equilibrium concepts, Cambridge University Press, Mc Graw Hill (2002)

56. S.H. Kim, S.W. Park and W.S. Gil, J. Appl. Polym. Sci., 67, 1383 (1998)

57. C. Marco, G. Ellis, M.A. Gómez, J.M. Arribas, J. Appl. Polym. Sci., 88, 2261 (2003)

58. E.J. Clark and J.D. Hoffman, Macromolecules 17, 878 (1984)

59. J.D. Hoffman, G.T. Davies and J.J. Lauritzen, Treatise on Solid State Chemistry, Vol.3, N.B. Hannay Ed., Plenum Press (1976), New York

60. J.D. Hoffman, Polymer 24, 3 (1983)

61. A.O. Ibhadon, J. Appl. Polym. Sci., 71, 579 (1999) 
62. J.J. Janimak and S.Z.D. Cheng, J. Polym. Eng., 10, 21 (1991)

63. B. Monasse and J.M. Haudin, Coll. Polym. Sci., 266, 679 (1988)

64. E.B. Bond, J.E. Spruiell and J.S. Lin, J. Polym. Sci. Polym. Phys., 37, 3050 (1999)

65. J.D. Hoffman, L.J. Frolen, G.S. Ross G.S and J.J. Lauritzen, J. Res. Natl. Bur. Stand., 79A, 671 (1975)

66. H.N. Beck, J. Appl. Polym. Sci., 19, 371 (1975)

67. J. Menczel and J. Varga, J. Therm. Anal. Cal., 28, 11 (1983)

68. Y. Fena, X. Jin and J.N. Hay, J. Appl. Polym. Sci., 69, 2089 (1988)

69. J. Yin, S. Wang, Y. Zhang and Y. Zhang, J. Polym. Sci. Polym. Phys., 43, 1914 (2005)

70. C. Li, D. Zhang and Z. Li, J. Appl. Polym. Sci., 85, 2644 (2002)

71. J. Ma, S. Zhang, Z.Z. Qi, G. Li and H. Hu, J. Appl. Polym. Sci., 83, 1978 (2002)

72. C. Wang C and C.R. Liu, Polymer 40, 289 (1999)

73. M. Razavi-Nouri, M. Ghorbanzadeh-Ahangari, A. Fereidoon, M. Jahanshahi, Polym. Test., 28, 46 (2009)

74. M. Mucha and Z.J. Krolikowski, J. Therm. Anal. Cal., 74, 549 (2003)

\section{TABLES}


Table 1. $T_{p}$ and $T_{10}$ values obtained for PP/MWCNT composites under dynamic crystallization cycles from the melt. Values of long spacing, $L$, calculated from SAXS measurements are included.

\begin{tabular}{|c|c|c|c|c|c|c|c|c|c|}
\hline \multirow{3}{*}{$\begin{array}{c}\% \\
\text { MWCNT }\end{array}$} & \multicolumn{8}{|c|}{$R\left({ }^{\circ} \mathrm{C} \cdot \mathrm{min}^{-1}\right)$} & \multirow{3}{*}{$\begin{array}{c}L \\
\text { (A) }\end{array}$} \\
\hline & \multicolumn{2}{|c|}{20} & \multicolumn{2}{|c|}{10} & \multicolumn{2}{|c|}{5} & \multicolumn{2}{|c|}{2} & \\
\hline & $\begin{array}{l}T_{10} \\
\left({ }^{\circ} \mathrm{C}\right)\end{array}$ & $\begin{array}{l}\mathrm{Tp} \\
\left({ }^{\circ} \mathrm{C}\right)\end{array}$ & $\begin{array}{l}T_{10} \\
\left({ }^{\circ} \mathrm{C}\right)\end{array}$ & $\begin{array}{c}\mathrm{Tp} \\
\left({ }^{\circ} \mathrm{C}\right)\end{array}$ & $\begin{array}{c}T_{10} \\
\left({ }^{\circ} \mathrm{C}\right)\end{array}$ & $\begin{array}{c}T p \\
\left({ }^{\circ} \mathrm{C}\right)\end{array}$ & $\begin{array}{c}T_{10} \\
\left({ }^{\circ} \mathrm{C}\right)\end{array}$ & $\begin{array}{c}\mathrm{Tp} \\
\left({ }^{\circ} \mathrm{C}\right)\end{array}$ & \\
\hline 0 & 110.1 & 105.6 & 117.6 & 112.0 & 119.6 & 116.0 & 123.7 & 120.7 & 100 \\
\hline 0.1 & 116.9 & $\overline{113.6}$ & $\overline{123.8}$ & $\overline{119.6}$ & 125.5 & 122.9 & $\overline{129.6}$ & $\overline{127.2}$ & 119 \\
\hline 0.25 & 117.8 & 114.5 & 124.3 & 120.4 & 127.2 & 124.5 & 131.9 & 129.1 & 121 \\
\hline 0.50 & 120.5 & $\overline{116.8}$ & $\overline{125.6}$ & 122.7 & 129.3 & 126.5 & 133.7 & $\overline{131.1}$ & 122 \\
\hline 1 & 119.9 & 116.7 & 125.8 & 122.0 & 128.8 & 126.0 & 133.4 & 130.5 & 130 \\
\hline
\end{tabular}

Table 2. Values of the isothermal rate constant $k$ calculated from Equation 7.

\begin{tabular}{|l|l|l|l|l|l|}
\hline \multirow{2}{*}{ Tc $\left({ }^{\circ} \mathrm{C}\right)$} & \multicolumn{5}{|c|}{$k .10^{5}\left(\mathrm{~min}^{-\mathrm{n}}\right)$} \\
\cline { 2 - 6 } & $\mathrm{W}_{\text {MWCNT }}=0$ & \multicolumn{1}{|c|}{0.1} & \multicolumn{1}{|c|}{0.25} & 0.5 & 1 \\
\hline 126 & 2020 & & & & \\
\hline 127 & 1052 & & & & \\
\hline 128 & 535 & & & & \\
\hline 129 & 258 & & & & \\
\hline 130 & 126 & & & & \\
\hline 131 & 78 & & 5700 & 12295 & \\
\hline 132 & 37 & 3370 & 2328 & 6512 & \\
\hline 133 & 15 & 1645 & 1169 & 2843 & 5699 \\
\hline 134 & & 814 & 555 & 1369 & 2843 \\
\hline 135 & & 374 & 265 & 667 & 1486 \\
\hline 136 & & 186 & 135 & 338 & 760 \\
\hline 137 & & 86 & 67 & 211 & 394 \\
\hline 138 & & 42 & 38 & 105 & 202 \\
\hline 139 & & 21 & 20 & 52 & 113 \\
\hline 140 & & 9 & 10 & & 61 \\
\hline 141 & & 6 & & & 32 \\
\hline 142 & & & & & 17 \\
\hline 143 & & & & & 9 \\
\hline 144 & & & & & \\
\hline
\end{tabular}




\section{FIGURES}
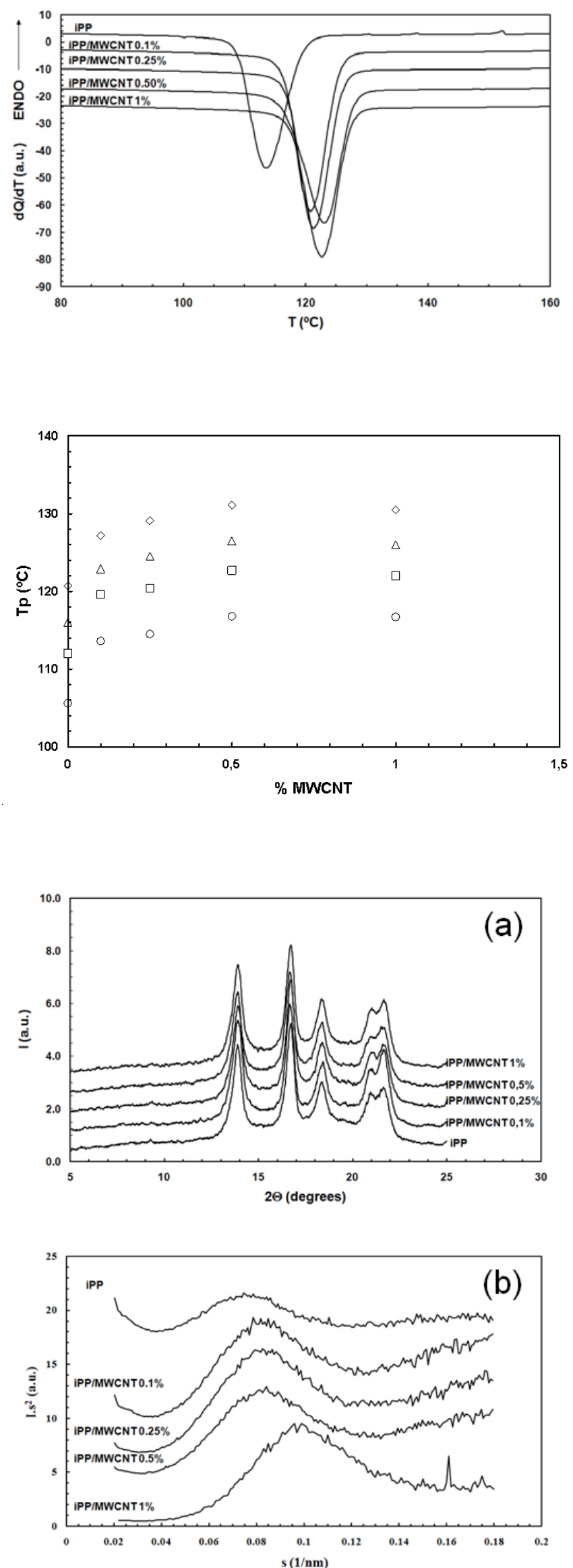

Figure 1. Crystallization exotherms recorded from the melt for iPP and its composite with MWCNT (concentrations shown) at a cooling rate of $10^{\circ} \mathrm{C} \cdot \mathrm{min}^{-1}$.

Figure 2. Variation of the $T_{p}$ values with MWCNT composition; (O) $20^{\circ} \mathrm{C} \cdot \mathrm{min}^{-1}$, (口) $10^{\circ} \mathrm{C} \cdot \mathrm{min}^{-1},(\triangle) 5^{\circ} \mathrm{C} \cdot \mathrm{min}^{-1}, \quad(\diamond)$ $2^{\circ} \mathrm{C} \cdot \mathrm{min}^{-1}$.

Figure 3. (a) WAXS and (b) SAXS diffractograms of iPP and iPP/MWCNT composites recorded at room temperature after crystallization from the melt at $10^{\circ} \mathrm{C} \cdot \mathrm{min}^{-1}$. 


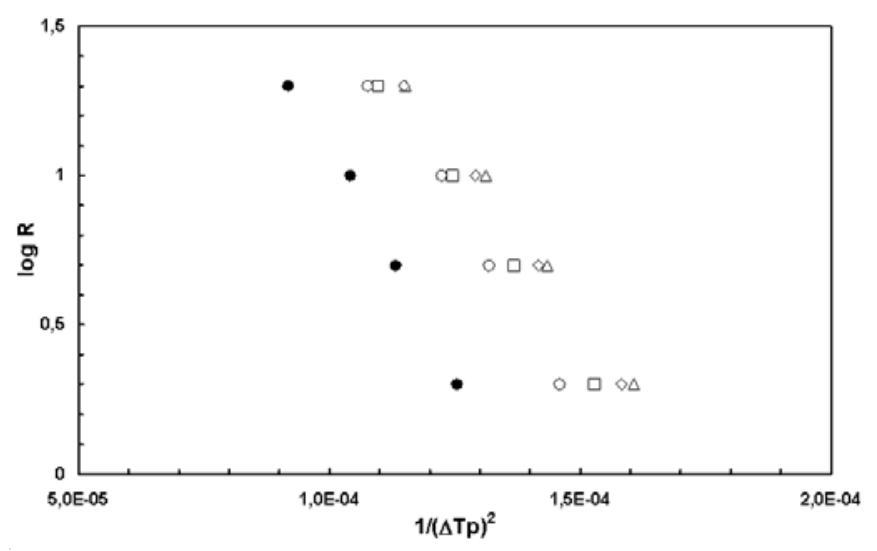

Figure 4. Plot of $\log \mathrm{R}$ vs $1 / \Delta \mathrm{T}_{\mathrm{p}}{ }^{2}$, according the Dobreva's approach. iPP, $(\bigcirc) \quad$ iPP/MWCNT 0.1\%, $(\square)$ iPP/MWCNT 0.25\%, $(\triangle)$ iPP/MWCNT 0.5\%, ( $\diamond) \mathrm{iPP} / \mathrm{MWCNT} 1 \%$.

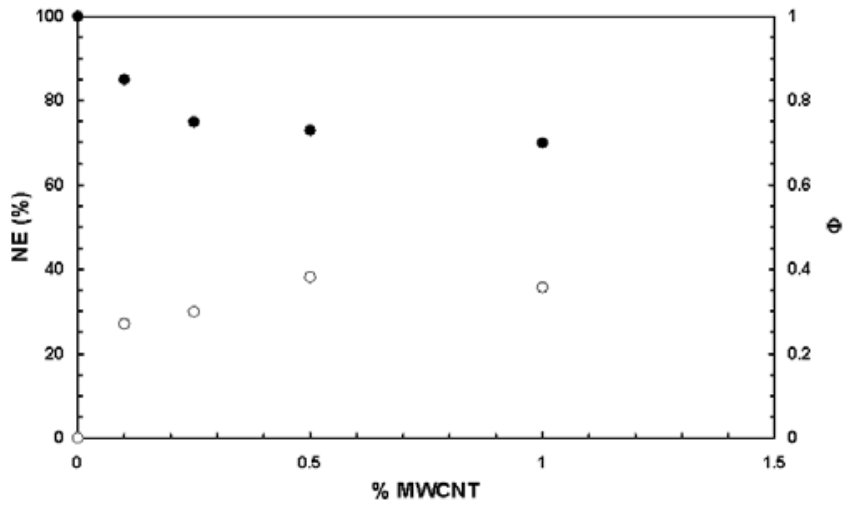

Figure 5. Variation of $\Phi(\bigcirc)$ and NE $(\mathrm{O})$, according the eq. 4 and 6 , with $\ominus \quad$ MWCNT composition.
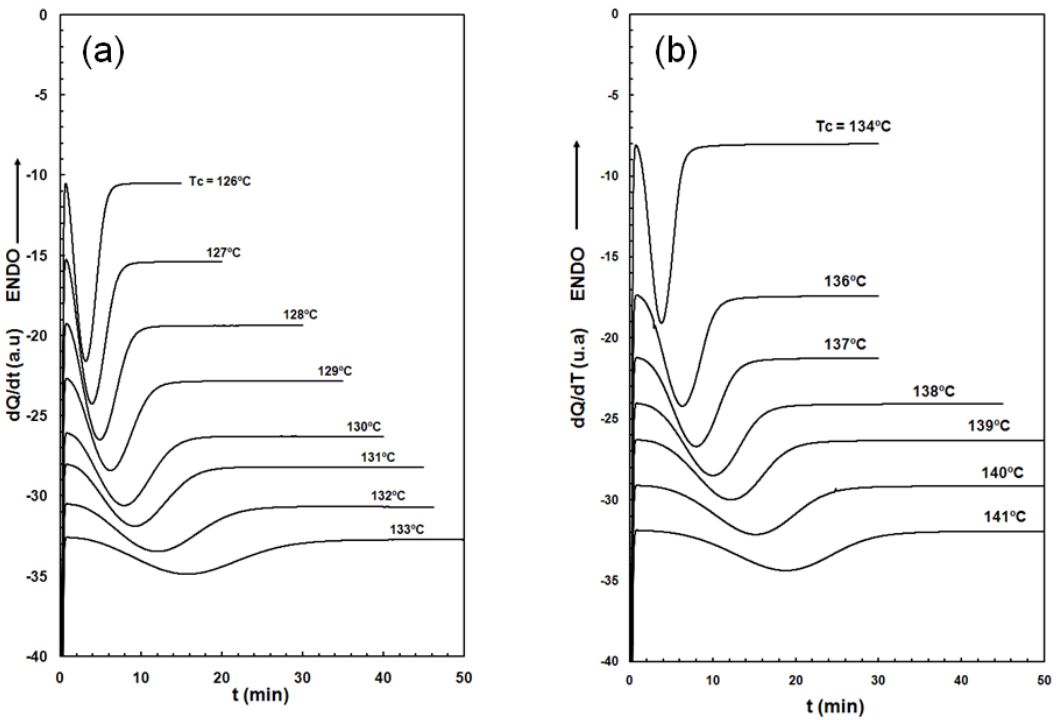

Figure 6. Crystallization exotherms for (a) raw iPP and (b) iPP/MWCNT $0.25 \%$, under isothermal conditions at the indicated crystallization temperatures. The baselines are shifted along the ordinate axis (arbitrary units) for clarity. 

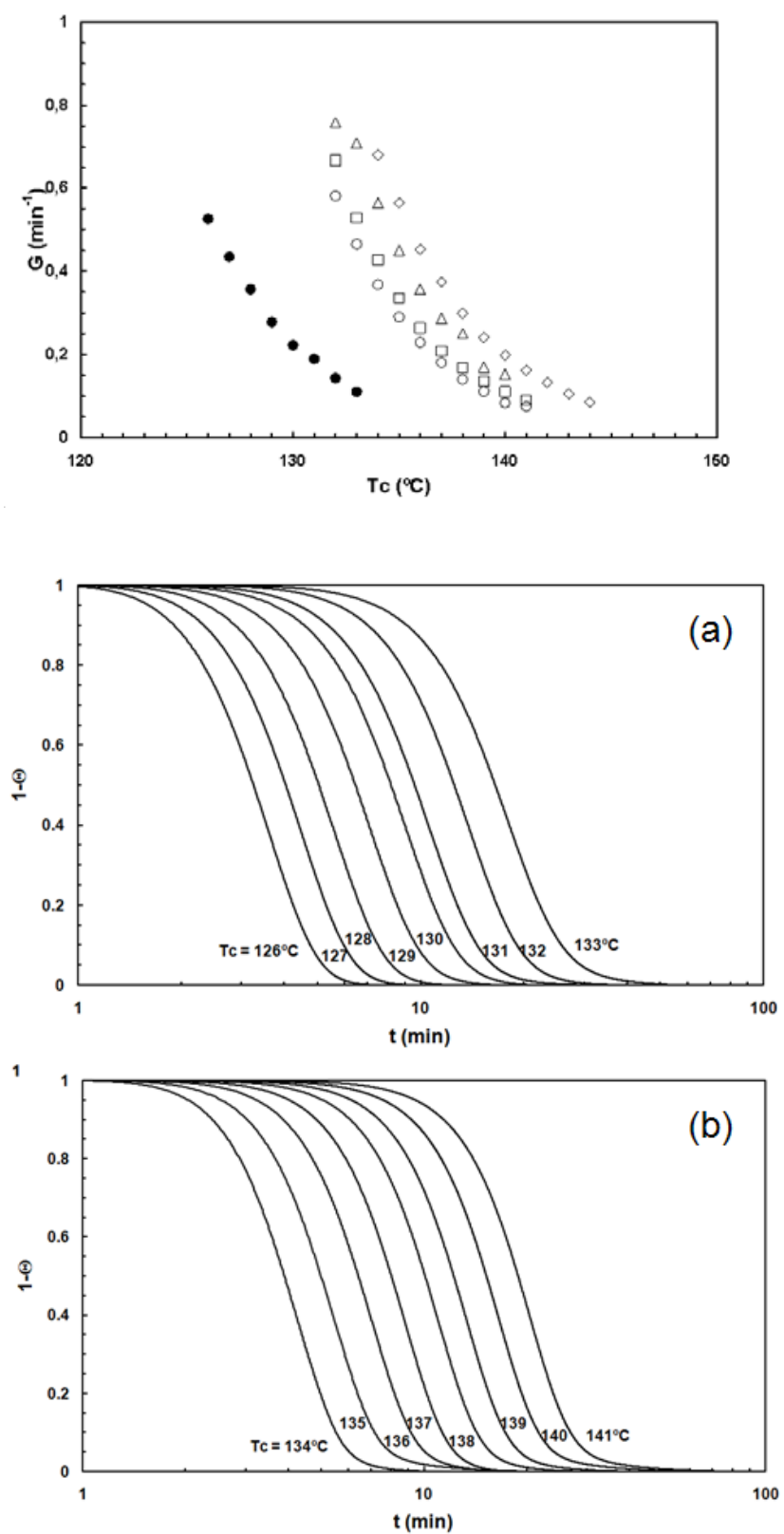

Figure 7. Variation in the isothermal crystallization rate, $G$ with the crystallization temperature. (O) iPP, $(\mathrm{O}) \mathrm{iPP} / \mathrm{MWCNT}$ $0.1 \%, \quad(\square) \quad \mathrm{iPP} / \mathrm{MWCNT} \quad 0.25 \%, \quad(\triangle)$ iPP/MWCNT 0.5\%, $(\diamond)$ iPP/MWCNT $1 \%$.

Figure 8. Variation in the crystalline conversion as a function of time is given for (a) neat iPP and (b) iPP/MWCNT 0.25\% composite, at the indicated crystallization temperatures.
Figure 9. DSC thermograms for the heating cycle at $5{ }^{\circ} \mathrm{C} \cdot \mathrm{min}^{-1}$ of (a) iPP, (b) iPP/MWCNT 0.1\% and (c) iPP/MWCNT 0.25\%, after isothermal crystallization from the melt at the indicated crystallization temperatures. The baselines are shifted along the ordinate axis (arbitrary units) for clarity.

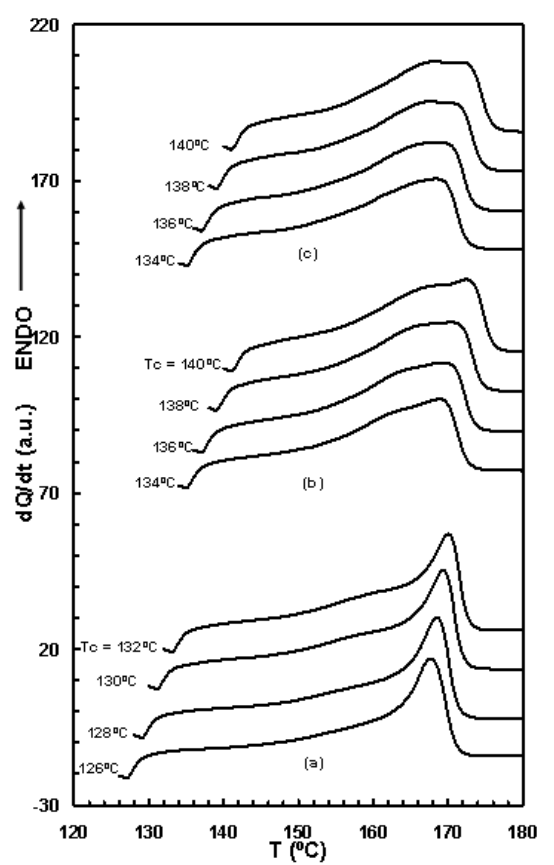



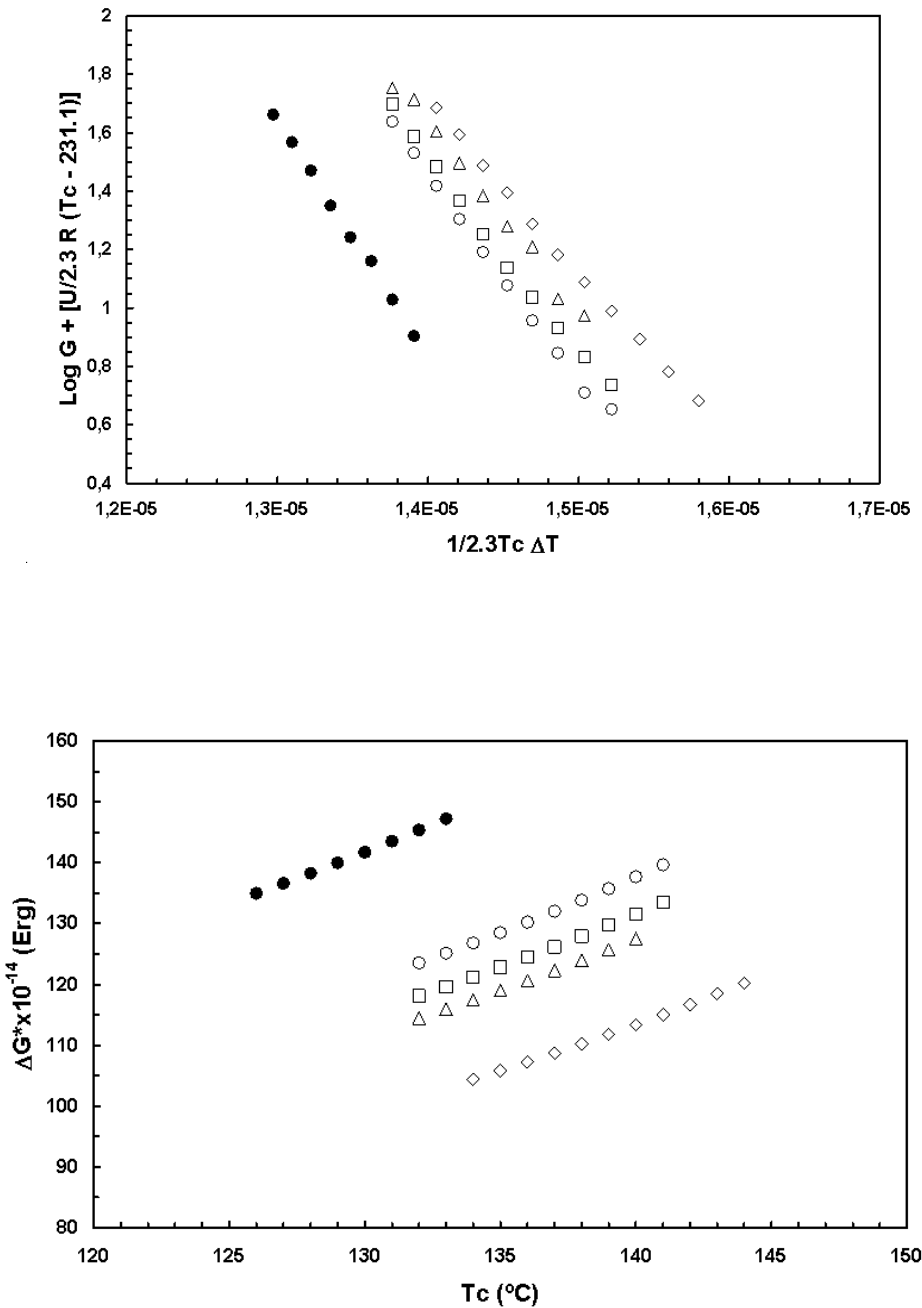

Figure 10. Temperature coefficient for all the materials studied, as determined by equation 8 . (О) iPP, $(\bigcirc)$ iPP/MWCNT 0.1\%, $(\square)$ iPP/MWCNT $\quad 0.25 \%, \quad(\triangle)$ iPP/MWCNT $\quad 0.5 \%, \quad(\diamond)$ iPP/MWCNT 1\%

Figure 11. Variation in the free energy of nucleation, $\Delta G^{*}$, as a function of the crystallization temperature. (O) iPP, $(\mathrm{O})$ iPP/MWCNT $\quad 0.1 \%, \quad(\square)$ iPP/MWCNT $\quad 0.25 \%, \quad(\triangle)$ iPP/MWCNT $\quad 0.5 \%, \quad(\diamond)$ iPP/MWCNT 1\%. 